\title{
Treatment of peripheral exudative hemorrhagic chorioretinopathy by intravitreal injections of ranibizumab
}

This article was published in the following Dove Press journal:

Clinical Ophthalmology

6 June 2012

Number of times this article has been viewed

\author{
Kei Takayama' \\ Tosio Enoki ${ }^{1,2}$ \\ Teruo Kojima ${ }^{1,2}$ \\ Sho Ishikawa' \\ Masaru Takeuchi' \\ 'Department of Ophthalmology, \\ National Defense Medical College, \\ Saitama, Japan; ${ }^{2}$ Enoki Clinic, Saitama, \\ Japan
}

\begin{abstract}
Peripheral exudative hemorrhagic chorioretinopathy (PEHCR) is a rare disorder that sometimes causes sudden subretinal and/or vitreous hemorrhage. Choroidal neovascularization is involved in the pathogenesis, but the etiology is unknown. Treatments with photocoagulation, cryopexy, and intravitreal bevacizumab injection have been reported. However, the therapeutic effect of intravitreal injection with ranibizumab for PEHCR is unclear. A 70-year-old woman visited our department because of sudden loss of superior visual field in her left eye. She had a history of surgical removal of hematoma due to subretinal hemorrhage associated with age-related macular degeneration 5 years ago. Peripheral subretinal hemorrhage was observed in the left eye, and fluorescein and indocyanine green angiography revealed choroidal neovascularization in the subretinal hemorrhagic region. PEHCR was diagnosed. Considering her past history, intravitreal ranibizumab injection was used for treatment. After three injections in the left eye, subretinal hemorrhage and choroidal neovascularization resolved completely. No recurrence was observed during 1 year of follow-up. This case demonstrates that intravitreal injection of ranibizumab is an effective treatment for PEHCR with subretinal hemorrhage.
\end{abstract}

Keywords: peripheral exudative hemorrhagic chorioretinopathy, ranibizumab, intravitreal injection, choroidal neovascularization

\section{Introduction}

Peripheral exudative hemorrhagic chorioretinopathy (PEHCR) is a rare disorder of the peripheral retina characterized by either a hemorrhagic or an exudative retinal degenerative process. ${ }^{1}$ Since the first report of this condition by Reese and Jones ${ }^{2}$ in 1962, a few cases have been reported in the literature. ${ }^{3,4}$ More recently, Shields et $\mathrm{al}^{5}$ reported 173 cases of PEHCR. They showed that PEHCR is predominantly a disease of elderly women, and manifests as bilateral lesions located in the temporal area between the equator and the ora serrata. Most PEHCR cases are accompanied by age-related macular degeneration, and sometimes cause sudden extensive subretinal and vitreous hemorrhage. The etiology is unknown, but involvement of peripheral choroidal neovascularization has been suggested. ${ }^{6,7}$ Intravitreal injection of antivascular endothelial growth factor antibodies, such as bevacizumab and ranibizumab, is so far the most effective treatment for macular diseases accompanied by choroidal neovascularization. ${ }^{8-10}$ Cryoretinopexy and photocoagulation ${ }^{11}$ have been used for the treatment of PEHCR, and the efficacy of intravitreal injection of bevacizumab $(2.5 \mathrm{mg}$ in $0.1 \mathrm{~mL}$; Genentech/Roche, San Francisco, CA) has been reported recently. ${ }^{12-15}$ We report a case in which intravitreal injection of ranibizumab was effective for the
Correspondence: Masaru Takeuchi Department of Ophthalmology, National Defense Medical College, 3-2 Namiki, Tokorozawa, Saitama 359-85 I3, Japan Tel +4 2993 I5 I I

$\mathrm{Fax}+429955332$

Email masatake@ndmc.ac.jp 
treatment of PEHCR with choroidal neovascularization presenting with extensive subretinal hemorrhage.

\section{Case report}

A 70-year-old woman visited our department because of a subjective sensation of a defective superior visual field in her left eye for 3 days before presentation. Cataract surgery had been performed in both eyes 8 years earlier and intraocular lenses had been implanted. She had no past history of diabetic mellitus, hypertension, or hyperlipidemia. On examination, her best-corrected visual acuity was $20 / 20$ in the right eye and 1/20 in the left eye, and intraocular pressures were $14 \mathrm{mmHg}$ and $15 \mathrm{mmHg}$, respectively.
Fundus examination revealed extensive subretinal hemorrhage in the inferior temporal region near the arcade vessels of the left eye (Figure 1A and B) and exudative age-related macular degeneration with a fibrotic scar in the left eye. Fibrotic macular degeneration was also observed in the left eye (Figure 1A), which might have resulted from vitrectomy for removal of subretinal hematoma associated with age-related macular degeneration 4 years earlier. No lesion was found in the right eye. Fluorescein angiography and indocyanine angiography revealed choroidal neovascularization corresponding to the region of subretinal hemorrhage (Figure 1A-F). PEHCR was diagnosed, and intravitreal injection of ranibizumab (Lucentis $^{\circledR}$; Novartis, Basel, Switzerland) was given in

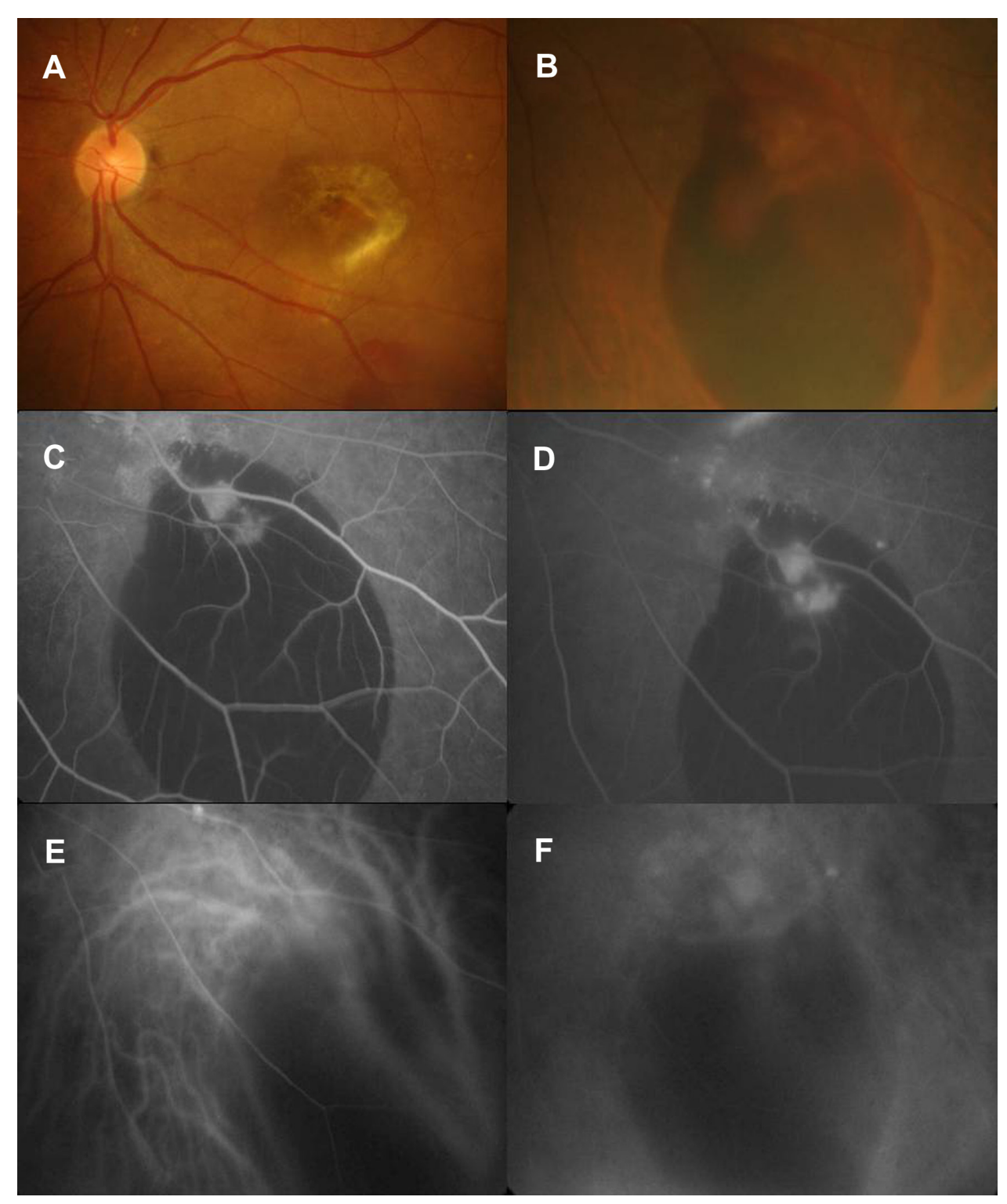

Figure I Fundus findings of the left eye before ranibizumab treatment. Fundus photographs (A) and (B) depict age-related macular degeneration (A) and subretinal hemorrhage (B) in temporal inferior region of macula. Fluorescein angiographic (C) and (D) and indocyanine green angiographic (E) and (F) findings reveal choroidal neovascularization corresponding (arrows) to the region of subretinal hemorrhage. 


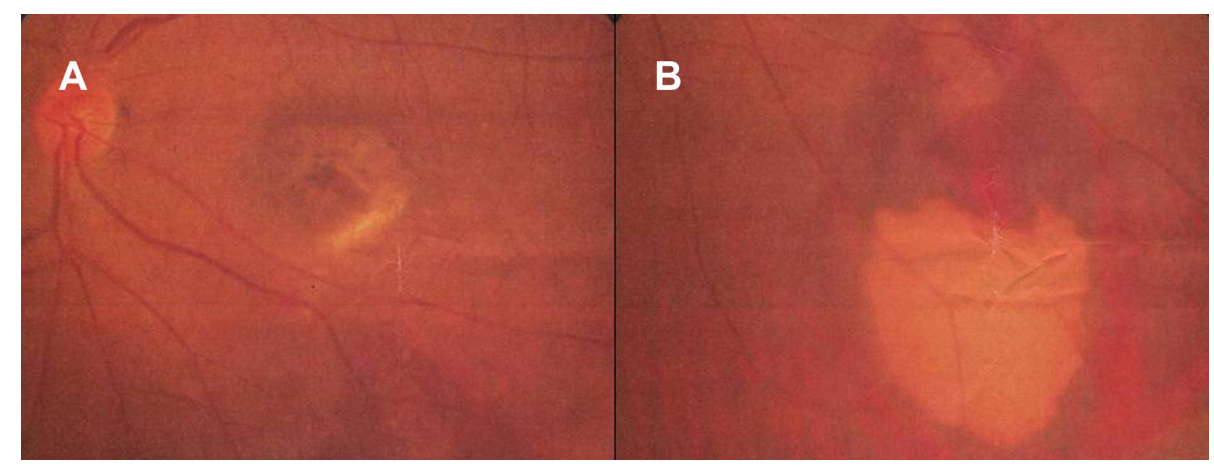

Figure 2 Fundus findings of the left eye after the first intravitreal ranibizumab injection.

Note: Subretinal hemorrhage outside the arcade vessels has obviously decreased, and the hemorrhagic area has become smaller than before treatment.

accordance with the protocol for treatment of age-related macular degeneration. ${ }^{16}$ After the first intravitreal injection of ranibizumab, the subretinal hemorrhage was obviously reduced compared with before treatment (Figure 2). Therefore, the injection was repeated at monthly intervals.
After the third injection, ophthalmoscopic examination showed complete resolution of subretinal hemorrhage (Figure $3 \mathrm{~A}$ and $\mathrm{B}$ ), and fluorescein angiography and indocyanine angiography showed reduction of choroidal neovascularization corresponding to the region of subretinal

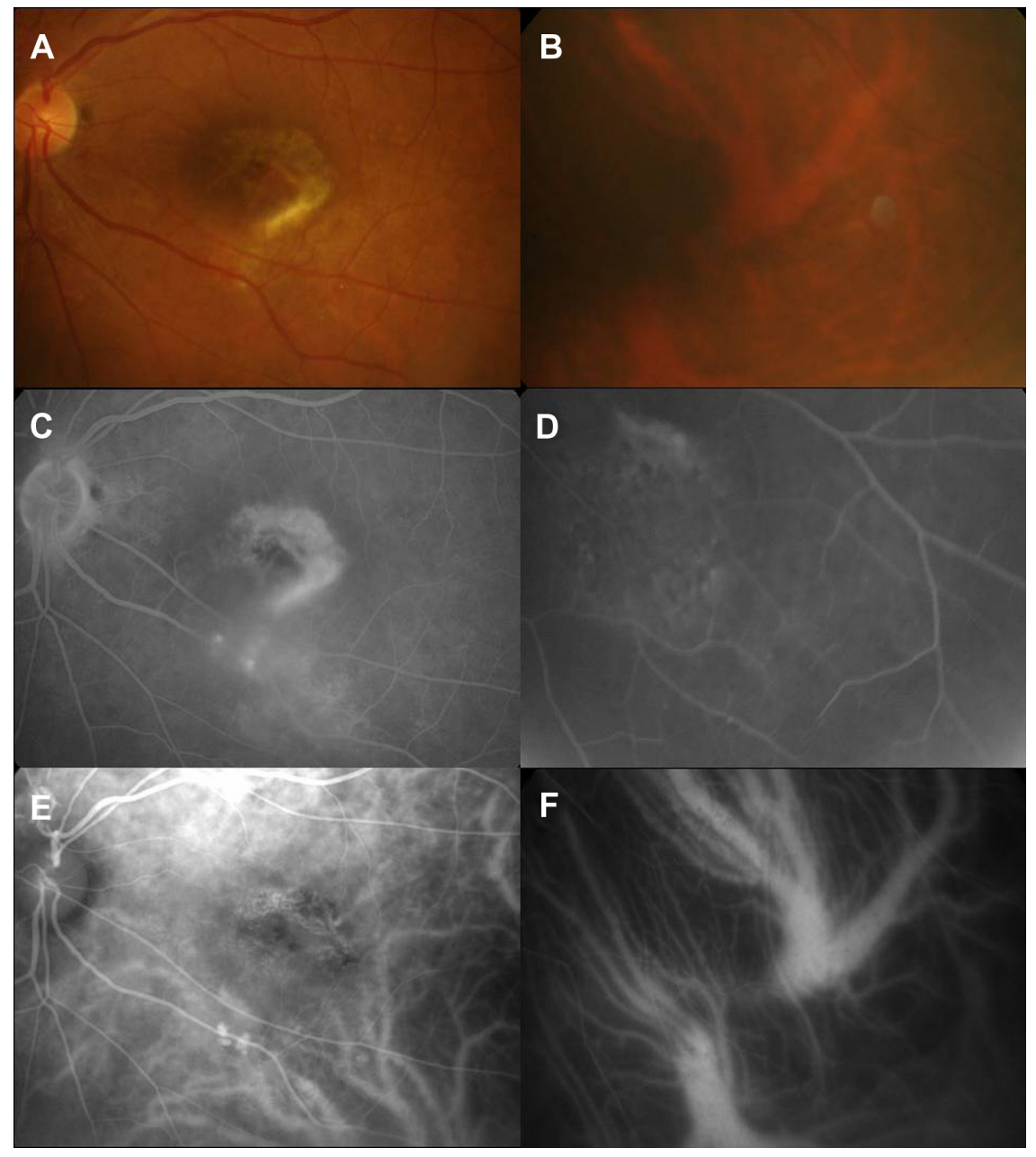

Figure 3 Fundus findings after three intravitreal ranibizumab injections. Fundus photographs (A) and (B) show disappearance of subretinal hemorrhage. No choroidal neovascularization and subretinal hemorrhage in the corresponding area are seen on fluorescein angiography (D) and indocyanine green angiography (F). However, there are some choroidal neovascularizations (arrows) in the posterior pole of the left eye (C) and (E). 
hemorrhage before treatment (Figure 3C-F), although bestcorrected visual acuity in the left eye remained unchanged at $1 / 20$ because of fibrotic macular degeneration. No recurrence of choroidal neovascularization-induced retinal lesions, including subretinal hemorrhage, and no adverse effects of intravitreal ranibizumab injection were observed during one year after the final injection.

\section{Discussion}

In this case, PEHCR developed in an elderly woman and was accompanied with age-related macular degeneration. Moreover, the lesion with subretinal hemorrhage was located at the temporal retina. These features correspond to the characteristics reported by Shields et al. ${ }^{5}$ Past reports ${ }^{6,7,11-15}$ have suggested that polypoidal choroidal neovascularization was the origin of age-related macular degeneration. In this case, fluorescein angiography and indocyanine angiography revealed choroidal neovascularization corresponding to the region of subretinal hemorrhage. The origin of this case was considered to be the same as those in past reports. Generally, PEHCR has a favorable prognosis, but recurring hemorrhage sometimes enlarges the lesion, resulting in macular degeneration and visual loss. ${ }^{17}$

Therefore, laser photocoagulation, cryoretinopexy, and intravitreal bevacizumab injection have been used for the treatment of PEHCR. Although laser photocoagulation and cryoretinopexy are beneficial if the causative peripheral vascular nets can be identified, ${ }^{18}$ their efficacy is uncertain in other conditions. On the contrary, laser photocoagulation may exacerbate subretinal hemorrhage, ${ }^{12}$ and induce cystoid macular edema presumably secondary to confluent ablative therapy. ${ }^{6}$ Cryoretinopexy may also worsen subretinal hemorrhage and cause subretinal fibrosis. ${ }^{12}$ These treatments are useful to achieve rapid resolution in some cases of PEHCR, but do not appear to be useful in improving the visual outcome. ${ }^{1}$ Photodynamic therapy with verteporfin is useful in patients with subfoveal choroidal neovascularization, but often enlarges chorioretinal atrophy after treatment. ${ }^{18}$

Recently, the efficacy of intravitreal bevacizumab injection for PEHCR has been reported. ${ }^{12-15}$ After three injections at monthly intervals, vision improved and lesions remained stable, with some regression of subretinal hemorrhage. No further subretinal hemorrhage was noted during postoperative convalescence and the retina remained flat and attached. ${ }^{13}$ However, bevacizumab is currently approved for clinical use in the treatment of cancers, such as colon cancer and metastatic non-small-cell lung cancer, and is not approved for ocular vascular diseases in Japan. Only ranibizumab is approved for the treatment of age-related macular degeneration by intravitreal injection route. Therefore, although intravitreal ranibizumab injection for PEHCR has not been reported, we used ranibizumab instead of bevacizumab as an antivascular endothelial growth factor antibody in the present case. The results of this case indicate the possibility that the curative efficacy of ranibizumab for PEHCR would be equivalent to that of bevacizumab.

\section{Disclosures}

The authors have no proprietary interests in any of the materials used in this study. This study received no financial support.

\section{References}

1. Annesley WH. Peripheral exudative hemorrhagic chorioretinopathy. Trans Am Ophthalmol Soc. 1980;(78):321-364.

2. Reese AB, Jones IS. Hematomas under the retinal pigment epithelium. Am J Ophthalmol. 1962;53:897-910.

3. Bloome MA, Ruiz RS. Massive spontaneous subretinal hemorrhage. Am J Ophthalmol. 1978;86(5):630-637.

4. Silva VB, Brockhurst RJ. Hemorrhagic detachment of the peripheral retinal pigment epithelium. Arch Ophthalmol. 1976;94(8): $1295-1300$.

5. Shields CL, Salazar PF, Mashayekhi A, Shields JA. Peripheral exudative hemorrhagic chorioretinopathy simulating choroidal melanoma in 173 eyes. Ophthalmology. 2009;116(3):529-535.

6. Vine AK, Johnson MW. Peripheral choroidal neovascularization. Eur J Ophthalmol. 1996;6(1):44-49.

7. Mantel I, Uffer S, Zografos L. Peripheral exudative hemorrhagic chorioretinopathy: a clinical, angiographic, and histologic study. Am J Ophthalmol. 2009;148(6):932-938.

8. Jonas JB, Tao Y, Schlichtenbrede FC. Intravitreal bevacizumab for exudative age-related macular degeneration in clinical practice. $J$ Ocul Pharmacol Ther. 2011;27(5):467-470.

9. Davis J, Olsen TW, Stewart M, Sternberg P Jr. How the comparison of age-related macular degeneration treatments trial results will impact clinical care. Am J Ophthalmol. 2011;152(4):509-514.

10. Stone EM. A very effective treatment for neovascular macular degeneration. N Engl J Med. 2006;355(14):1493-1495.

11. Kim YT, Kang SW, Lee J-H, Chung SE. Peripheral exudative hemorrhagic chorioretinopathy in Korean patients. Jpn J Ophthalmol. 2010;54(3):227-231.

12. Alforja MS, Sabater N, Giralt J, Adán A, Pelegrín L, Casaroli-Marano R. Intravitreal bevacizumab injection for peripheral exudative hemorrhagic chorioretinopathy. Jpn J Ophthalmol. 2011;55(4):425-427.

13. Gonzales JA, Kapoor KG, Gibran SK. Peripheral exudative hemorrhagic chorioretinopathy: A clinical, angiographic, and histologic study. Am J Ophthalmol. 2010;149(6):1013-1014.

14. Barkmeier AJ, Kadikoy H, Holz ER, Carvounis PE. Regression of serous macular detachment due to peripheral exudative hemorrhagic chorioretinopathy following intravitreal bevacizumab. Eur J Ophthalmol. 2011;21(4):506-508.

15. Rishi P, Das A, Sarate P, Rishi E. Management of peripheral polypoidal choroidal vasculopathy with intravitreal bevacizumab and indocyanine green angiography-guided laser photocoagulation. Indian J Ophthalmol. 2012;60(1):60-63. 
16. Heier JS, Antoszyk AN, Pavan PR, et al. Ranibizumab for treatment of neovascular age-related macular degeneration: a Phase I/II multicenter, controlled, multidose study. Ophthalmology. 2006;113(4):642. e1-e4.

17. Uyama M, Wada M, Nagai Y, et al. Polypoidal choroidal vasculopathy: natural history. Am J Ophthalmol. 2002;133(5):639-648.
18. Collaer N, James C. Peripheral exudative and hemorrhagic chorioretinopathy ... the peripheral form of age-related macular degeneration? Report on 2 cases. Bull Soc Belge Ophtalmol. 2007;305:23-26.

\section{Publish your work in this journal}

Clinical Ophthalmology is an international, peer-reviewed journal covering all subspecialties within ophthalmology. Key topics include: Optometry; Visual science; Pharmacology and drug therapy in eye diseases; Basic Sciences; Primary and Secondary eye care; Patien Safety and Quality of Care Improvements. This journal is indexed on

Submit your manuscript here: http://www.dovepress.com/clinical-ophthalmology-journal

\section{Dovepress}

PubMed Central and CAS, and is the official journal of The Society of Clinical Ophthalmology (SCO). The manuscript management system is completely online and includes a very quick and fair peer-review system, which is all easy to use. Visit http://www.dovepress.com/ testimonials.php to read real quotes from published authors. 